Check for updates

Cite this: Mater. Adv., 2022, 3,2793

Received 19th October 2021, Accepted 6th February 2022 DOI: 10.1039/d1ma00967b

rsc.li/materials-advances

\section{Performance and reaction mechanisms of tin compounds as high-capacity negative electrodes of lithium and sodium ion batteries}

\begin{abstract}
Hiroki Kotaka, ${ }^{\text {ab }}$ Hiroyoshi Momida (D) ac and Tamio Oguchi (D) *ac
We study the characteristics of tin sulfide $(\mathrm{SnS})$ and tin phosphate $\left(\mathrm{Sn}_{4} \mathrm{P}_{3}\right)$ as negative electrodes for rechargeable $\mathrm{Li}$ and $\mathrm{Na}$ ion batteries by first-principles calculations. The electrode reaction formulae during the discharge processes are fully revealed by the energy analyses of ternary $A-S n-B(A=L i, N a$; $B=S, P)$ phase diagrams. The phase diagrams of ternary systems with the constructed convex-hull surfaces show a possible reaction route considering intermediate products in discharge reactions. The voltage-capacity curves along the reaction paths obtained from the ternary phase diagrams are calculated. To evaluate the battery performance of tin compounds, we analyze the volume expansion ratios of the materials by incorporation of $\mathrm{Li}$ and $\mathrm{Na}$ ions. In the case of $\mathrm{Li} / \mathrm{SnS}, \mathrm{Na} / \mathrm{SnS}$, and Li/Sn${ }_{4} \mathrm{P}_{3}$, it is found that the conversion reactions and subsequently the alloying reactions proceed stepwise in the electrode, contributing to their high capacities. In $\mathrm{Na} / \mathrm{Sn}_{4} \mathrm{P}_{3}$, however, the conversion and alloying reactions proceed alternately or simultaneously, showing more complex reactions than the others.
\end{abstract}

\section{Introduction}

In the last few decades, the invention of lithium-ion batteries has dramatically changed our lives and led to various developments through the storage and efficient use of electrical energy. Nowadays, electrical energy is widely used in mobile phones, cameras, laptops, power tools, etc. and has become an indispensable technology deeply connected to our lives. As the use of power sources is further expanding in the market and becoming larger in size, there is a demand for a secondary battery that is good in terms of both cost and performance.

In recent years, the environmental damage caused due to industrial development has become a global concern, so the effective use of power generation systems using natural energies including solar power has been promoted. Until now, one of the reasons why renewable energy power generation has not been mainstream is the disadvantage that the amount of power supply is not constant. The amount of power supply from renewable energy sources increases or decreases due to the environmental factors on which the system depends (such as day or night and weather). To stably operate renewable energy

\footnotetext{
${ }^{a}$ Elements Strategy Initiative for Catalysts and Batteries, Kyoto University, Kyoto 615-8245, Japan

${ }^{b}$ Innovation Technology Center, Central Technical Research Laboratory, ENEOS Corporation, 8 Chidoricho, Naka-Ku, Yokohama 231-0815, Japan

${ }^{c}$ Institute of Scientific and Industrial Research, Osaka University, Ibaraki, Osaka

567-0047, Japan.E-mail: oguchi@sanken.osaka-u.ac.jp
}

power supplies, temporary storage of the generated energy is necessary. A large stationary power supply with a high energy density is useful for reducing the difference in electricity consumption between day and night.

The construction of large-scale energy storage facilities requires secondary batteries that excel in both cost and performance. Currently, Li-ion batteries, ${ }^{1-5}$ which are typically composed of a $\mathrm{LiCoO}_{2}$ cathode and a $\mathrm{C}$ anode, use expensive rare metals (such as $\mathrm{Li}$ and $\mathrm{Co}$ ) that are distributed through limited countries, and it is difficult to produce huge amounts of batteries enough to meet future requirements. It is necessary to develop battery storage systems that are good in terms of cost and performance as an alternative to the currently used Li-ion batteries. If rare metals can be replaced with relatively inexpensive and readily available elements, the mass production of rechargeable ion batteries becomes possible. In particular, Li, which plays a key role as charge carriers, is an expensive metal because of its limited production area. Materials research studies have been carried out for developing novel electrodes to replace $\mathrm{Li}$ with inexpensive elements such as $\mathrm{Na},{ }^{6-9} \mathrm{~K}$ and Mg. ${ }^{10-13}$

In typical Li-ion batteries, Li-insertion and Li-intercalation reactions have been known as the primary atomistic mechanisms in $\mathrm{LiCoO}_{2}$ cathode and $\mathrm{C}$ anode reactions, respectively, with high cycle performance. In $\mathrm{Na}$ ion batteries, however, the carrier ions have a larger ionic radius than $\mathrm{Li}$, and thus suitable electrode materials are needed to promote the insertion/intercalation reactions, although superior battery performance has 
not been easily realized for large-size ionic species. ${ }^{14-16}$ Since the conversion or alloying reactions generate compounds or alloys with carrier ions, ${ }^{17-21}$ which differ from an initial electrode material, the storage capacity does not strongly depend on the ionic radius but is determined by the reaction path expected from the phase stability of the negative electrode material and the carrier ions. Even for $\mathrm{Na}$ with a larger ionic radius than $\mathrm{Li}$, a higher storage capacity can be obtained for conversion-type electrodes. We have theoretically studied candidate anode and cathode materials with conversion-type electrochemical reactions applicable to $\mathrm{Na}$ batteries. ${ }^{22-27}$

The idea of using alloy-based negative electrodes, especially Sn-based materials due to their nontoxicity and low cost, has attracted great interest to achieve high capacities with low voltages. In this study, we focus our attention on Sn sulfides and phosphates ( $\mathrm{SnS}$ and $\mathrm{Sn}_{4} \mathrm{P}_{3}$ as initial electrode materials) as candidate materials for negative electrodes in both $\mathrm{Li}$ - and $\mathrm{Na}$ ion rechargeable batteries. Elemental $\mathrm{Sn}$ itself has been expected to be one of the candidate negative electrode materials because of its high capacity, sufficient Na-reserve ability, and high safety, and the alloying reactions producing Li-Sn or NaSn alloys have been considered to be key reaction mechanisms in Sn electrodes. ${ }^{28-34}$ However, Sn electrodes show significant deterioration of the cycle characteristics due to the large volume expansion with $\mathrm{Li}$ or $\mathrm{Na}$ absorption. ${ }^{28-34} \mathrm{Sn}$ oxides (such as $\mathrm{SnO}$ and $\mathrm{SnO}_{2}$ ) and sulfides (such as $\mathrm{SnS}_{2}$ ) have been experimentally studied as negative electrodes for Na-ion batteries, ${ }^{35-38}$ but their reversible capacities are still lower than those of Sn.

One advantage of Sn-compound electrodes is that the capacity can be expected to further increase due to the multi-step reaction processes including conversion reactions in addition to alloying reactions. Also, if the volume changes between products before and after the reactions are small, the performance degradation due to the volume expansion can be reduced. In Sn-compound negative electrodes, it is expected that two types of battery reactions including conversion reactions (possibly producing binary $\mathrm{Li} / \mathrm{Na}-\mathrm{S} / \mathrm{P}$ or ternary $\mathrm{Li} / \mathrm{Na}-\mathrm{Sn}-\mathrm{S} / \mathrm{P}$ products) and alloying reactions (possibly producing $\mathrm{Li} / \mathrm{Na}-\mathrm{Sn}$ alloys) can proceed sequentially, and the former may improve the longevity of the cycle characteristics of anodes. Many experimental studies have been conducted aiming to develop negative electrode materials with Sn-containing structures, which can achieve better electrochemical performance with both good cycle performance and high capacities for $\mathrm{Li}^{-}$and Na-ion rechargeable batteries, ${ }^{39-45}$ but detailed microscopic reaction mechanisms are not clear yet.

To systematically understand the Li- and Na-ion battery performances of $\mathrm{Sn}$ sulfides and phosphates, we calculate the discharge reaction processes for $\mathrm{SnS}$ and $\mathrm{Sn}_{4} \mathrm{P}_{3}$ negative electrodes. We compare the differences in battery performance and the reaction pathways depending on various compounds (S or $\mathrm{P}$ ) and the carrier ions ( $\mathrm{Li}$ or $\mathrm{Na}$ ). The first-principles electronic state calculation method is used to accurately predict the charge/discharge reaction processes and to calculate the voltage-capacity characteristics, which enables us to propose powerful battery material candidates from a theoretical point of view. From the theoretical viewpoint, extensive energy analyses on ternary phase diagrams clarified the voltage-capacity curves and the volume expansion ratios during the discharge processes in the Sn-compound electrodes. In this study, the battery performance is predicted by comparing the formation energies from first-principles calculations, and our results will be a clue to design superior materials if we can find regularity in the reaction process of each tin additive and ion carrier.

\section{Materials and methods}

To obtain the discharge reaction formulae of the SnS and $\mathrm{Sn}_{4} \mathrm{P}_{3}$ electrodes during the discharge processes in half-cell systems with $\mathrm{Li}$ and $\mathrm{Na}$ (described as $\mathrm{Li} / \mathrm{SnS}, \mathrm{Na} / \mathrm{SnS}, \mathrm{Li} / \mathrm{Sn}_{4} \mathrm{P}_{3}$ and $\mathrm{Na}$ / $\mathrm{Sn}_{4} \mathrm{P}_{3}$ ), we theoretically search for the most stable reaction pathways on the ternary $\mathrm{A}-\mathrm{Sn}-\mathrm{B}(\mathrm{A}=\mathrm{Li}, \mathrm{Na}$; $\mathrm{B}=\mathrm{S}, \mathrm{P})$ energetic phase diagrams by using formation energy analyses with firstprinciples calculations. To construct ternary energetic phase diagrams, we consider all the $\mathrm{A}_{x} \mathrm{Sn}_{y} \mathrm{~B}_{z}$ materials that are listed in the crystal structure databases Crystallography Open Database $^{46}$ and AtomWork, ${ }^{47}$ from which the experimentally known crystal structures have been collected. The formation energies $(H)$ of $\mathrm{A}_{x} \mathrm{Sn}_{y} \mathrm{~B}_{z}$ are calculated with reference to elemental $A$, Sn and $B$ as

$$
H=E\left[\mathrm{~A}_{x} \mathrm{Sn}_{y} \mathrm{~B}_{z}\right]-(x E[\mathrm{~A}]+y E[\mathrm{Sn}]+z E[\mathrm{~B}])
$$

where $E[X]$ stands for the total energy of a material $X$. As reference materials, we calculate bcc-lithium, bcc-sodium, $\beta$ tin, $\alpha$-sulfur, and Hittorf's phosphorus. For each ternary system, the convex hull surfaces are constructed, showing the thermodynamically stable phases at respective elemental composition ratios.

The first-principles calculations are performed using the VASP code, ${ }^{48,49}$ which is based on density functional theory (DFT) within generalized gradient approximation (GGA) by Perdew, Burke, and Ernzerhof. ${ }^{50}$ The wave functions are expressed in projector augmented wave and plane-wave basis sets. ${ }^{51}$ The lattice constants and atomic positions of all the materials are fully optimized by first-principles calculations.

The discharge reaction formulae can be obtained from the theoretical ternary phase diagrams along the SnS-A and $\mathrm{Sn}_{4} \mathrm{P}_{3}-$ A lines considering intermediate products. Based on the obtained reaction formulae, we study the electrochemical properties of $\mathrm{Li} / \mathrm{SnS}, \mathrm{Na} / \mathrm{SnS}, \mathrm{Li} / \mathrm{Sn}_{4} \mathrm{P}_{3}$ and $\mathrm{Na} / \mathrm{Sn}_{4} \mathrm{P}_{3}$ systems. The voltage values can be calculated by estimating the DFT total energy differences for the given reaction formulae. ${ }^{52-54}$ (In the first-principles calculations, the kinetics of structural reversibility is difficult to consider under an external voltage or current applied in the charging process, especially for the present conversion/alloying-type electrodes, and understanding the reversibility will require significant advances in theoretical and modelling methodologies.).

The electrochemical compound and alloy formation by lithiation or sodiation processes is advantageous for achieving 
a higher capacity, but cycle stability is typically reduced by the volume expansion induced by incorporation of larger carrier ions. We investigate the volume expansion ratio during the discharge reaction processes and clarify the reactions that cause large volume expansion.

\section{Results and discussion}

\section{Phase diagrams of A-Sn-B (A = Li, Na; B = S, P)}

To theoretically clarify the discharge reaction processes in the tin-compound negative electrodes, we calculate the formation energies of possible reaction products using the first-principles calculations. To specify the reaction products likely formed during discharge reactions in the electrodes, we construct the ternary phase diagrams with formation energies for the A-Sn-B $(\mathrm{A}=\mathrm{Li}, \mathrm{Na} ; \mathrm{B}=\mathrm{S}, \mathrm{P})$ systems as shown in Fig. 1. At each composition ratio, the calculated formation energies of several $\mathrm{A}_{x} \mathrm{Sn}_{y} \mathrm{~B}_{z}$ materials (shown by colored circles in Fig. 1) show negative values, indicating that the thermodynamically stable phases (thus the reaction products) strongly depend on the composition ratios. We determine the combinations of the most stable phases by constructing the convex hull surfaces (shown by grey lines in Fig. 1) of formation energies.

On the $\mathrm{Sn}-\mathrm{S}$ and $\mathrm{Sn}-\mathrm{P}$ edge lines, $\mathrm{SnS}$ and $\mathrm{Sn}_{4} \mathrm{P}_{3}$ (and also $\mathrm{SnS}_{2}$ and $\mathrm{SnP}_{3}$ ) are found to be thermodynamically stable, supporting that they can be actually synthesizable as the initial electrode materials. On the $\mathrm{Li}-\mathrm{Sn}$ and $\mathrm{Na}-\mathrm{Sn}$ edge lines, several
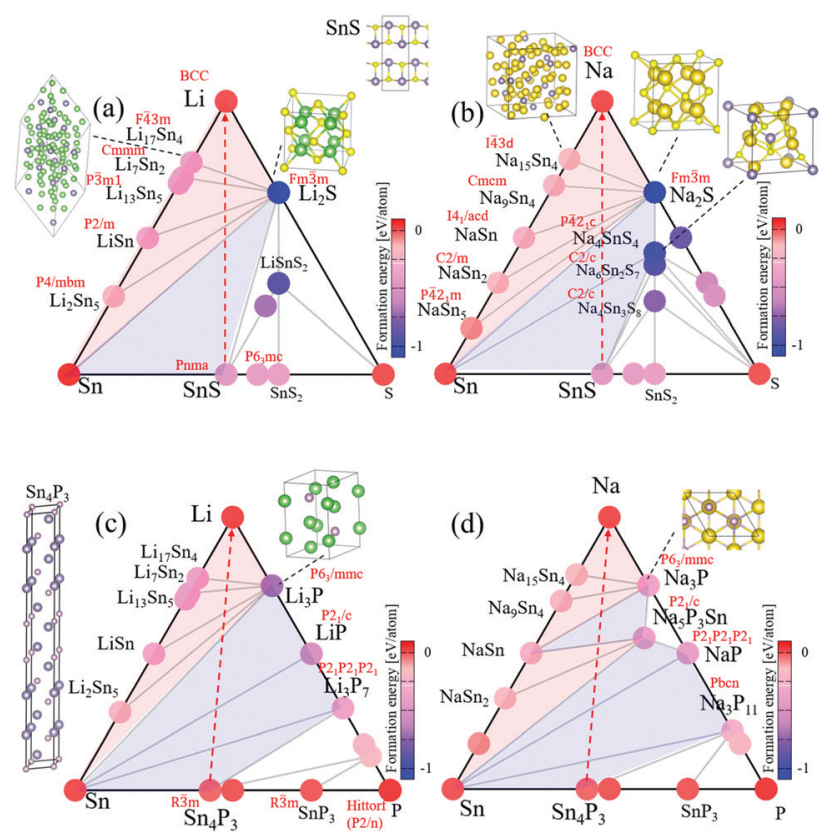

Fig. 1 The ternary phase diagrams of (a) Li-Sn-S, (b) Na-Sn-S, (c) Li-Sn$\mathrm{P}$, and (d) $\mathrm{Na}-\mathrm{Sn}-\mathrm{P}$. All the experimentally known materials listed in the crystal structure databases Crystallography Open Database ${ }^{46}$ and AtomWork $^{47}$ are calculated by DFT, and their formation energies [eqn (1)] are shown by colored circles. When the electrode reaction path (red broken lines) crosses the convex-hull lines (grey lines), phase separation into materials at each vertex can occur. The conversion and alloying reactions occur in the sky blue and pink shaded regions, respectively.
Li-Sn $\left(\mathrm{Li}_{2} \mathrm{Sn}_{5}, \mathrm{LiSn}, \mathrm{Li}_{13} \mathrm{Sn}_{5}, \mathrm{Li}_{7} \mathrm{Sn}_{2}\right.$ and $\left.\mathrm{Li}_{17} \mathrm{Sn}_{4}\right)$ and $\mathrm{Na}-\mathrm{Sn}$ $\left(\mathrm{NaSn}_{5}, \mathrm{NaSn}_{2}, \mathrm{NaSn}, \mathrm{Na}_{9} \mathrm{Sn}_{4}\right.$ and $\left.\mathrm{Na}_{15} \mathrm{Sn}_{4}\right)$ binary alloy phases are found to be stable, consistent with previous reports. ${ }^{28-32}$

Notable differences among the four systems are found on/ near the A-B ( $=\mathrm{Li}, \mathrm{Na} ; \mathrm{B}=\mathrm{S}, \mathrm{P})$ edges. In Fig. 1(a and b), $\mathrm{Li}_{2} \mathrm{~S}$ and $\mathrm{Na}_{2} \mathrm{~S}$ have the lowest energies, respectively, showing that they are very stable. The ternary materials such as $\mathrm{Na}_{4} \mathrm{SnS}_{4}$ in Fig. 1(b) also show very low energies, indicating that the ternary phases are possibly involved in discharge reactions. In Fig. 1(c and $\mathrm{d}$ ), several binary $\mathrm{Li}-\mathrm{P}$ and $\mathrm{Na}-\mathrm{P}$ materials are found to be stable. The ternary material $\left(\mathrm{Na}_{5} \mathrm{P}_{3} \mathrm{Sn}\right.$ in the $\mathrm{Na}-\mathrm{Sn}-\mathrm{P}$ system) can be thermodynamically stable, but no stable ternary material is found in the Li-Sn-P system. The convex-hull surfaces of the phosphide systems are shallower than those of the sulfide systems, especially in the A-B sides, indicating that Sn phosphides have lower voltages than Sn sulfides.

The phase diagrams with the convex-hull curves indicate the possible reaction routes of $\mathrm{SnS}$ and $\mathrm{Sn}_{4} \mathrm{P}_{3}$ electrodes with respect to $\mathrm{Li}$ and $\mathrm{Na}$. The discharge reactions can proceed along the SnS- $A$ and $\mathrm{Sn}_{4} \mathrm{P}_{3}-\mathrm{A}(\mathrm{A}=\mathrm{Li}, \mathrm{Na})$ lines (shown by red broken lines in Fig. 1) with increasing $A$ concentration, assuming constant composition ratios of $\mathrm{Sn}: \mathrm{S}=1: 1$ and $\mathrm{Sn}: \mathrm{P}=4: 3$. Following the reaction paths, we can find most likely dischargereaction products. There is no single-phase product just on the reaction paths, but the mixed phases at both ends of convex hulls can be produced in the electrodes when the reaction path crosses the convex hull lines.

\section{Discharge reaction formulae}

Table 1 lists the full discharge reaction formulae of SnS and $\mathrm{Sn}_{4} \mathrm{P}_{3}$ with $\mathrm{Li}$ and $\mathrm{Na}$ including the intermediate processes, which are derived from Fig. 1. The reaction processes in both SnS and $\mathrm{Sn}_{4} \mathrm{P}_{3}$ have a common character for $\mathrm{Li}$ electrodes. Firstly, binary Li-B (B = S, P) materials with the elemental Sn substance are produced, called conversion reactions. In the conversion reactions, only $\mathrm{Li}_{2} \mathrm{~S}$ is produced in the $\mathrm{Li} / \mathrm{SnS}$ system, but the three phases of $\mathrm{Li}_{3} \mathrm{P}_{7}, \mathrm{LiP}$, and $\mathrm{Li}_{3} \mathrm{P}$ are produced step by step in the $\mathrm{Li} / \mathrm{Sn}_{4} \mathrm{P}_{3}$ system as the Li concentration increases. After the conversion reactions, the separated $\mathrm{Sn}$ reacts with $\mathrm{Li}$ producing the binary Li-Sn alloys, and subsequently the Li-Sn alloys further react with Li generating more $\mathrm{Li}$-rich $\mathrm{Li}-\mathrm{Sn}$ alloys, called alloying reactions. In both $\mathrm{Li}$ / $\mathrm{SnS}$ and $\mathrm{Li} / \mathrm{Sn}_{4} \mathrm{P}_{3}$ systems, five $\mathrm{Li}-\mathrm{Sn}$ phases of $\mathrm{Li}_{2} \mathrm{Sn}_{5}, \mathrm{LiSn}$, $\mathrm{Li}_{13} \mathrm{Sn}_{5}, \mathrm{Li}_{7} \mathrm{Sn}_{2}$, and $\mathrm{Li}_{17} \mathrm{Sn}_{4}$ are sequentially generated in the alloying reactions. Therefore, one conversion and five alloying reactions in $\mathrm{Li} / \mathrm{SnS}$ (six-step reactions in total) and three conversion and five alloying reactions in $\mathrm{Li} / \mathrm{Sn}_{4} \mathrm{P}_{3}$ (eight-step reactions in total) can occur step by step as the $\mathrm{Li}$ concentration increases in the electrodes.

In the case of $\mathrm{Na}$ carrier ions, however, the discharge reactions in the tin-compound electrodes show more complicated processes because the ternary compounds are involved in the reactions. In the $\mathrm{Na} / \mathrm{SnS}$ system, $\mathrm{Na}_{4} \mathrm{SnS}_{4}$ is produced in the early stage of conversion reactions, and then it is converted to $\mathrm{Na}_{2} \mathrm{~S}$ with the elemental $\mathrm{Sn}$ substance. After the conversion reactions, the alloying reactions generating five $\mathrm{Na}-\mathrm{Sn}$ phases 
Table 1 The discharge reaction equations of $\mathrm{SnS}$ and $\mathrm{Sn}_{4} \mathrm{P}_{3}$ with $\mathrm{Li}$ and $\mathrm{Na}$, which are derived from Fig. 1 . The calculated voltages $(V)$ and volume expansion ratios of products to $\mathrm{SnS}$ or $\mathrm{Sn}_{4} \mathrm{P}_{3}\left(\Omega / \Omega_{0}\right)$ are listed for each reaction

\begin{tabular}{|c|c|c|}
\hline & $V(\mathrm{~V})$ & $\Omega / \Omega_{0}$ \\
\hline \multicolumn{3}{|l|}{$\mathrm{Li} / \mathrm{SnS}$} \\
\hline $\mathrm{SnS}+2 \mathrm{Li} \rightarrow \mathrm{Li}_{2} \mathrm{~S}+\mathrm{Sn}$ & 1.57 & 1.44 \\
\hline $5 \mathrm{Sn}+2 \mathrm{Li} \rightarrow \mathrm{Li}_{2} \mathrm{Sn}_{5}$ & 0.69 & 1.54 \\
\hline $\mathrm{Li}_{2} \mathrm{Sn}_{5}+3 \mathrm{Li} \rightarrow 5 \mathrm{LiSn}$ & 0.67 & 1.68 \\
\hline $5 \mathrm{LiSn}+8 \mathrm{Li} \rightarrow \mathrm{Li}_{13} \mathrm{Sn}_{5}$ & 0.50 & 2.11 \\
\hline $2 \mathrm{Li}_{13} \mathrm{Sn}_{5}+9 \mathrm{Li} \rightarrow 5 \mathrm{Li}_{7} \mathrm{Sn}_{2}$ & 0.26 & 2.38 \\
\hline $\begin{array}{l}2 \mathrm{Li}_{7} \mathrm{Sn}_{2}+3 \mathrm{Li} \rightarrow \mathrm{Li}_{17} \mathrm{Sn}_{4} \\
\mathrm{Na} / \mathrm{SnS}\end{array}$ & 0.13 & 2.65 \\
\hline $4 \mathrm{SnS}+4 \mathrm{Na} \rightarrow \mathrm{Na}_{4} \mathrm{SnS}_{4}+3 \mathrm{Sn}$ & 1.30 & 1.60 \\
\hline $\mathrm{Na}_{4} \mathrm{SnS}_{4}+4 \mathrm{Na} \rightarrow \mathrm{Sn}+4 \mathrm{Na}_{2} \mathrm{~S}$ & 1.05 & 2.09 \\
\hline $5 \mathrm{Sn}+\mathrm{Na} \rightarrow \mathrm{NaSn}_{5}$ & 0.66 & 2.10 \\
\hline $2 \mathrm{NaSn}_{5}+3 \mathrm{Na} \rightarrow 5 \mathrm{NaSn}_{2}$ & 0.47 & 2.25 \\
\hline $\mathrm{NaSn}_{2}+\mathrm{Na} \rightarrow 2 \mathrm{NaSn}$ & 0.43 & 2.53 \\
\hline $4 \mathrm{NaSn}+5 \mathrm{Na} \rightarrow \mathrm{Na}_{9} \mathrm{Sn}_{4}$ & 0.14 & 3.14 \\
\hline \multicolumn{2}{|l|}{$\mathrm{Li} / \mathrm{Sn}_{4} \mathrm{P}_{3}$} & 4.03 \\
\hline $7 \mathrm{Sn}_{4} \mathrm{P}_{3}+9 \mathrm{Li} \rightarrow 28 \mathrm{Sn}+3 \mathrm{Li}_{3} \mathrm{P}_{7}$ & 1.05 & 1.37 \\
\hline $\mathrm{Li}_{3} \mathrm{P}_{7}+4 \mathrm{Li} \rightarrow 7 \mathrm{LiP}$ & 0.95 & 1.42 \\
\hline $\mathrm{LiP}+2 \mathrm{Li} \rightarrow \mathrm{Li}_{3} \mathrm{P}$ & 0.88 & 1.88 \\
\hline $5 \mathrm{Sn}+2 \mathrm{Li} \rightarrow \mathrm{Li}_{2} \mathrm{Sn}_{5}$ & 0.69 & 1.82 \\
\hline $\mathrm{Li}_{2} \mathrm{Sn}_{5}+3 \mathrm{Li} \rightarrow 5 \mathrm{LiSn}$ & 0.67 & 1.99 \\
\hline $5 \mathrm{LiSn}+8 \mathrm{Li} \rightarrow \mathrm{Li}_{13} \mathrm{Sn}_{5}$ & 0.50 & 2.50 \\
\hline $2 \mathrm{Li}_{13} \mathrm{Sn}_{5}+9 \mathrm{Li} \rightarrow 5 \mathrm{Li}_{7} \mathrm{Sn}_{2}$ & 0.26 & 2.82 \\
\hline $2 \mathrm{Li}_{7} \mathrm{Sn}_{2}+3 \mathrm{Li} \rightarrow 5 \mathrm{Li}_{17} \mathrm{Sn}_{4}$ & 0.13 & 3.17 \\
\hline \multicolumn{3}{|l|}{$\mathrm{Na} / \mathrm{Sn}_{4} \mathrm{P}_{3}$} \\
\hline $11 \mathrm{Sn}_{4} \mathrm{P}_{3}+9 \mathrm{Na} \rightarrow 44 \mathrm{Sn}+3 \mathrm{Na}_{3} \mathrm{P}_{11}$ & 0.92 & 1.40 \\
\hline $\mathrm{Na}_{3} \mathrm{P}_{11}+8 \mathrm{Na} \rightarrow 11 \mathrm{NaP}$ & 0.65 & 1.64 \\
\hline $3 \mathrm{NaP}+2 \mathrm{Na}+\mathrm{Sn} \rightarrow \mathrm{Na}_{5} \mathrm{P}_{3} \mathrm{Sn}$ & 0.59 & 1.89 \\
\hline $2 \mathrm{Sn}+\mathrm{Na} \rightarrow \mathrm{NaSn}_{2}$ & 0.46 & 2.03 \\
\hline $\mathrm{NaSn}_{2}+\mathrm{Na} \rightarrow 2 \mathrm{NaSn}$ & 0.43 & 2.29 \\
\hline $\mathrm{Na}_{5} \mathrm{P}_{3} \mathrm{Sn}+5 \mathrm{Na} \rightarrow \mathrm{NaSn}+3 \mathrm{Na}_{3} \mathrm{P}$ & 0.22 & 3.06 \\
\hline $4 \mathrm{NaSn}+5 \mathrm{Na} \rightarrow \mathrm{Na}_{9} \mathrm{Sn}_{4}$ & 0.14 & 3.82 \\
\hline $\mathrm{Na}_{9} \mathrm{Sn}_{4}+6 \mathrm{Na} \rightarrow \mathrm{Na}_{15} \mathrm{Sn}_{4}$ & 0.10 & 4.91 \\
\hline
\end{tabular}

of $\mathrm{NaSn}_{5}, \mathrm{NaSn}_{2}, \mathrm{NaSn}, \mathrm{Na}_{9} \mathrm{Sn}_{4}$, and $\mathrm{Na}_{15} \mathrm{Sn}_{4}$ proceed step by step. In the $\mathrm{Na} / \mathrm{Sn}_{4} \mathrm{P}_{3}$ system, it is found that the conversion and alloying reactions are not well divided by the Na concentrations in the electrode. Firstly, the binary $\mathrm{Na}_{3} \mathrm{P}_{11}$ and $\mathrm{NaP}$ and then the ternary $\mathrm{Na}_{5} \mathrm{SnP}_{3}$ are produced step by step generating elemental Sn. Secondly, the alloying reactions forming $\mathrm{NaSn}_{2}$ and NaSn proceed. Thirdly, the ternary $\mathrm{Na}_{5} \mathrm{SnP}_{3}$ reacts with $\mathrm{Na}$ producing $\mathrm{Na}_{3} \mathrm{P}$. Finally, the alloying reactions producing $\mathrm{Na}_{9} \mathrm{Sn}_{4}$ and $\mathrm{Na}_{15} \mathrm{Sn}_{4}$ occur. Therefore, $\mathrm{Na} / \mathrm{Sn}_{4} \mathrm{P}_{3}$ shows a mixture of reaction mechanisms, especially in the late discharge processes.

\section{Voltage-capacity characteristics}

Based on the reaction formulae obtained from the phase diagrams, we study the electrochemical properties of the halfcell systems of $\mathrm{SnS}$ and $\mathrm{Sn}_{4} \mathrm{P}_{3}$ vs. Li and Na. To evaluate the battery performances, we calculate and compare their voltagecapacity curves. The voltage values can be estimated by calculating the DFT total energy differences for a given reaction formula. $^{52-54}$ Fig. 2 shows the calculated voltage-capacity curves of the $\mathrm{Li} / \mathrm{SnS}, \mathrm{Na} / \mathrm{SnS}, \mathrm{Li} / \mathrm{Sn}_{4} \mathrm{P}_{3}$, and $\mathrm{Na} / \mathrm{Sn}_{4} \mathrm{P}_{3}$ systems. The calculated voltage values are also listed for each reaction in Table 1.
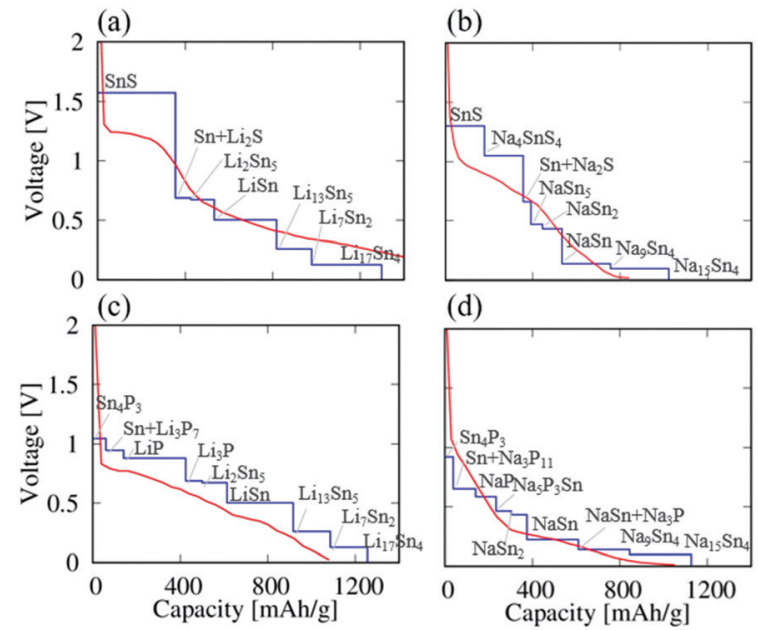

(d)

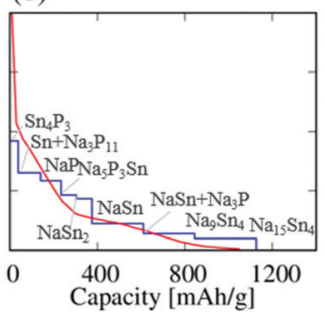

Fig. 2 The voltage-capacity curves of (a) Li/SnS, (b) Na/SnS, (c) Li/Sn $\mathrm{P}_{3}$ and (d) $\mathrm{Na} / \mathrm{Sn}_{4} \mathrm{P}_{3}$ systems as negative electrodes (blue solid lines). The experimental values of the first discharge processes (red solid lines) were taken from ref. 39 ( $\mathrm{Li} / \mathrm{SnS}), 27(\mathrm{Na} / \mathrm{SnS}), 42\left(\mathrm{Li} / \mathrm{Sn}_{4} \mathrm{P}_{3}\right)$, and $43\left(\mathrm{Na} / \mathrm{Sn}_{4} \mathrm{P}_{3}\right)$.

As can be seen in both $\mathrm{Li} / \mathrm{SnS}$ [Fig. 2(a)] and $\mathrm{Na} / \mathrm{SnS}$ [Fig. 2(b)], the SnS electrode shows an voltage over $1 \mathrm{~V}$ in the early reaction processes, in which the conversion reactions occur. In $\mathrm{Li} / \mathrm{SnS}$, the voltage is about $1.6 \mathrm{~V}$ up to about $350 \mathrm{~mA} \mathrm{~h} \mathrm{~g}{ }^{-1}$. Even in $\mathrm{Na} / \mathrm{SnS}$, high voltages of $1.1-1.3 \mathrm{~V}$ are estimated at the initial stage of reactions corresponding to the conversion reactions. The voltage values show a sudden drop to less than $0.7 \mathrm{~V}$ at a capacity of about $400 \mathrm{~mA} \mathrm{~h} \mathrm{~g}^{-1}$, where the alloying reactions start to take place. The voltages of $\mathrm{Na} / \mathrm{SnS}$ are smaller than those of $\mathrm{Li} / \mathrm{SnS}$ in the overall capacity range.

In $\mathrm{Li} / \mathrm{Sn}_{4} \mathrm{P}_{3}$ [Fig. 2(c)] and $\mathrm{Na} / \mathrm{Sn}_{4} \mathrm{P}_{3}$ [Fig. 2(d)], the voltage values are less than about $1 \mathrm{~V}$ in the whole capacity range (except for very beginning in $\mathrm{Li} / \mathrm{Sn}_{4} \mathrm{P}_{3}$ ), and the $\mathrm{Sn}_{4} \mathrm{P}_{3}$ electrodes show lower voltages by roughly $0.5 \mathrm{~V}$ than the $\mathrm{SnS}$ electrodes in the early discharge processes. In addition, the voltage drops in the $\mathrm{Sn}_{4} \mathrm{P}_{3}$ electrodes associated with the mechanism change from the conversion to the alloying reactions are moderate compared with the cases of $\mathrm{SnS}$ electrodes. In the $\mathrm{Sn}_{4} \mathrm{P}_{3}$ electrodes as well, the voltages of $\mathrm{Na} / \mathrm{Sn}_{4} \mathrm{P}_{3}$ are smaller than those of $\mathrm{Li} / \mathrm{Sn}_{4} \mathrm{P}_{3}$ in the overall capacity range.

In both $\mathrm{SnS}$ and $\mathrm{Sn}_{4} \mathrm{P}_{3}$, the voltages vs. Na are lower than those vs. $\mathrm{Li}$, and the theoretical capacities for $\mathrm{Na}$ are comparable to those for $\mathrm{Li}$. The $\mathrm{Sn}_{4} \mathrm{P}_{3}$ electrodes for both $\mathrm{Li}$ and $\mathrm{Na}$ involve a larger number of intermediate reactions compared with those in the SnS electrodes, which can contribute to smooth voltage-capacity profiles and may increase capacities in real materials.

We compare the calculated voltage-capacity curves with the reported experimental results. The experimental voltage-capacity curves of the first discharge process for $\mathrm{Li} / \mathrm{SnS},{ }^{39} \mathrm{Na} / \mathrm{SnS},{ }^{27}$ $\mathrm{Li} / \mathrm{Sn}_{4} \mathrm{P}_{3},{ }^{42}$ and $\mathrm{Na} / \mathrm{Sn}_{4} \mathrm{P}_{3}{ }^{43}$ are also plotted in Fig. 2. We can observe an overall agreement between the calculated and observed curves. In the $\mathrm{Sn}_{4} \mathrm{P}_{3}$ anode for Li-ion batteries, the conversion reactions ( $\mathrm{LiP}$ and $\mathrm{Li}_{3} \mathrm{P}$ ) and the subsequent alloying reactions $\left(\mathrm{Li}_{x} \mathrm{Sn}\right)$ have been experimentally considered, and 
the formation of $\mathrm{Li}_{13} \mathrm{Sn}_{5}$ is observed by XRD. ${ }^{42}$ In the $\mathrm{Sn}_{4} \mathrm{P}_{3}$ anode for $\mathrm{Na}$-ion batteries, the formation of $\mathrm{Na}_{15} \mathrm{Sn}_{4}$ and $\mathrm{Na}_{3} \mathrm{P}$ has been observed experimentally. ${ }^{43}$ In the $\mathrm{SnS}$ anode for Naion batteries, the discharge product of $\mathrm{Na}_{2} \mathrm{~S}$ has been confirmed by experiments. ${ }^{27}$ These experimentally observed products are actually included in the present reaction formulae.

To be precise, the voltage values differ between calculations and experiments within $0.3 \mathrm{~V}$ or less in size. In particular, the calculated voltages of $\mathrm{SnS}$ for $\mathrm{Li}$ and $\mathrm{Na}$ overestimate the experimental values in the early reaction processes, where the conversion reactions take place. Since we calculate the voltage values at each reaction step from the energy differences before and after the reactions assuming the reaction formulae, the theoretical voltage-capacity curves show ideal step functions. In experiments, the voltage-capacity curves usually depend on actual conditions such as temperature, current rate, sample shape and additive, and multiple conversion/alloying reactions can simultaneously occur in electrodes, especially at high temperatures. In addition, the discharge reactions near surfaces or inside the electrode particles can differ, and, perhaps, the reactions near surfaces proceed before those that occur inside. Therefore, the experimental voltage-capacity profiles typically do not show ideal step-like functions and have oblique shapes. It has been experimentally reported that electrolyte materials, which are not considered in this work, significantly affect battery performances for $\mathrm{Sn}_{4} \mathrm{P}_{3}$-based electrodes. $^{55}$

\section{Volume expansion ratios during discharge}

The formation of $\mathrm{Li} / \mathrm{Na}$ compounds and $\mathrm{Li} / \mathrm{Na}-\mathrm{Sn}$ alloys during the discharge reactions is advantageous for increasing the capacities, but it is expected that the cycle stability decreases due to the volume increase as the amount of carrier ions increases in the electrodes. In the case of the $\mathrm{Sn}$ anodes, significantly large volume expansion ratios of $260 \%$ for $\mathrm{Li}$ and $420 \%$ for $\mathrm{Na}$ have been reported. ${ }^{33,34}$ Based on the reaction processes summarized in Table 1 , we calculate the volume expansion ratios of the $\mathrm{SnS}$ and $\mathrm{Sn}_{4} \mathrm{P}_{3}$ electrodes with respect to the $\mathrm{Li} / \mathrm{Na}$ concentration in each reaction process. The volume expansion ratio is calculated as $\Omega / \Omega_{0}$, where $\Omega$ is the volume of products after lithiation or sodiation and $\Omega_{0}$ is the volume of SnS or $\operatorname{Sn}_{4} \mathrm{P}_{3}\left(\Omega_{0}=\Omega_{\mathrm{SnS}}\right.$ or $\left.\Omega_{\mathrm{Sn} 4 \mathrm{P} 3}\right)$ per $\mathrm{SnS}$ or $\mathrm{Sn}_{4} \mathrm{P}_{3}$.

Fig. 3 shows the calculated volume expansion ratios of the SnS and $\mathrm{Sn}_{4} \mathrm{P}_{3}$ electrodes (the initial materials as the references) during the discharge processes for $\mathrm{Li}$ and $\mathrm{Na}$ carrier ions. Generally, the volume expansion ratio is related to the number of $\mathrm{Li}$ or $\mathrm{Na}$ ions incorporated into the $\mathrm{SnS}$ or $\mathrm{Sn}_{4} \mathrm{P}_{3}$ electrode. $\mathrm{Sn}_{4} \mathrm{P}_{3}$ shows a slightly larger volume expansion than $\mathrm{SnS}$ in the entire capacity range for both $\mathrm{Li}$ and $\mathrm{Na}$ carrier ions. Therefore, $\mathrm{SnS}$ is better than $\mathrm{Sn}_{4} \mathrm{P}_{3}$ in terms of volume changes. For the Li carrier in the small capacity range near $400 \mathrm{~mA} \mathrm{~h} \mathrm{~g}^{-1}$, the volume of the $\mathrm{Sn}_{4} \mathrm{P}_{3}$ electrode largely increases due to the formation of $\mathrm{Li}_{3} \mathrm{P}$ compared with the $\mathrm{SnS}$ electrode generating $\mathrm{Li}_{2} \mathrm{~S}$. The difference of ionic radii between $\mathrm{Li}$ and $\mathrm{Na}$ ions essentially affects the volume expansion and therefore the cycle
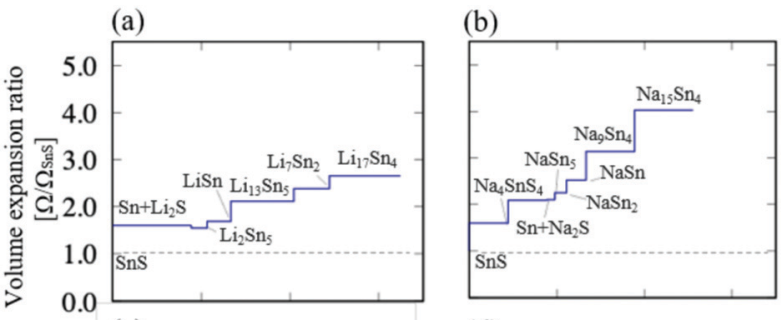

(c)

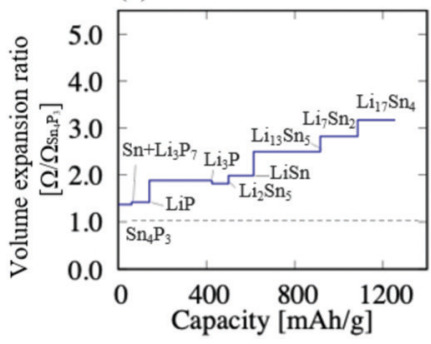

(d)

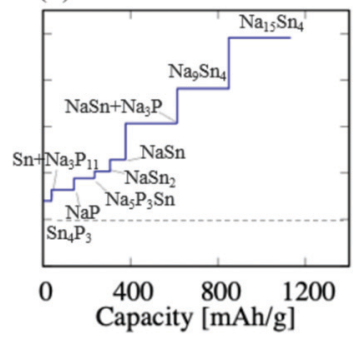

Fig. 3 The volume expansion ratios of (a) Li/SnS, (b) Na/SnS, (c) Li/Sn ${ }_{4} \mathrm{P}_{3}$ and (d) $\mathrm{Na} / \mathrm{Sn}_{4} \mathrm{P}_{3}$ as negative electrodes.

characteristics. Since the volumes of the Na compounds and alloys in the reactions are larger than those of Li compounds, the volume expansion in the whole capacity range is significantly large for the $\mathrm{Na}$ carrier ions, showing a larger slope for $\mathrm{Na}$ than for $\mathrm{Li}$. The volumes of the $\mathrm{Na}$ compounds $\left(\mathrm{Na}_{2} \mathrm{~S}\right.$ and $\left.\mathrm{Na}_{x} \mathrm{P}_{1-x}\right)$ are larger than those of the $\mathrm{Li}$ compounds for the same composition ratio.

Conversion/alloying-type electrodes usually suffer from such large volume changes, which cause electrode deterioration such as cracks and fractures of electrode materials, leading to degradation of cycle stability. ${ }^{56,57}$ This is the most difficult part in their practical applications, especially for $\mathrm{Na}$-ion batteries due to the larger ionic radius of $\mathrm{Na}$ than that of Li. Therefore, nanoparticles with smaller sizes or porous structures of the electrode materials, in which stress due to volume changes can be effectively relieved, may be particularly suitable for Na-ion battery applications, ${ }^{56,57}$ as experimentally reported for the Sn nanoparticle anodes. ${ }^{33}$

\section{Conclusions}

We investigate the battery characteristics of $\mathrm{SnS}$ and $\mathrm{Sn}_{4} \mathrm{P}_{3}$ materials as negative electrodes for both $\mathrm{Li}^{-}$and $\mathrm{Na}$-ion rechargeable batteries by first-principles calculations. We clarify the detailed discharge reaction processes in the electrodes from the energy analyses based on the first-principles calculations. Considering all the possible $\mathrm{A}_{x} \mathrm{Sn}_{y} \mathrm{~B}_{z}(\mathrm{~A}=\mathrm{Li}, \mathrm{Na} ; \mathrm{B}=\mathrm{S}, \mathrm{P})$ crystals that are listed in the databases, we calculate the ternary A-Sn-B phase diagrams with formation energies and construct the energy convex-hull surfaces. From the phase diagrams, we clarify the discharge reaction paths including intermediate reactions following the convex-hull curves.

In $\mathrm{SnS}$ and $\mathrm{Sn}_{4} \mathrm{P}_{3}$ for Li carrier-ions, it is found that first the conversion reactions producing the binary $\mathrm{Li}-\mathrm{S}$ and $\mathrm{Li}-\mathrm{P}$ compounds with elemental Sn proceed and then the alloying 
reactions forming the $\mathrm{Li}-\mathrm{Sn}$ alloys follow stepwise. In the case of $\mathrm{Na}$ ions, on the other hand, it is found that ternary materials are involved in the reactions, making the reaction processes complex, and the conversion and alloying reactions can proceed alternately and simultaneously in the $\mathrm{Na} / \mathrm{Sn}_{4} \mathrm{P}_{3}$ system. Based on the obtained reaction processes, we evaluate the voltage-capacity curves of $\mathrm{SnS}$ and $\mathrm{Sn}_{4} \mathrm{P}_{3} v s$. Li and Na. In both materials, the voltages for $\mathrm{Na}$ are lower than those for $\mathrm{Li}$, and the theoretical capacities for $\mathrm{Na}$ are comparable to those for $\mathrm{Li}$. In the case of $\mathrm{Na}$, we find a larger number of intermediate reaction processes than those for $\mathrm{Li}$, which may increase the capacities of the electrodes in Na-ion batteries. In terms of voltage values, $\mathrm{Sn}_{4} \mathrm{P}_{3}$ shows lower values than $\mathrm{SnS}$ for both Liand Na-ion batteries, especially in the early reaction stage, being suitable for anode materials.

In the discharge reactions, $\mathrm{Li} / \mathrm{Na}$ compounds and $\mathrm{Li} / \mathrm{Na}-\mathrm{Sn}$ alloys are formed in the electrodes, which is advantageous for increasing the capacity. However, it is expected that cycle performance decreases due to the volume expansion by incorporating carrier ions. We actually estimate the volume expansion ratio in each reaction process. Because the ionic radius of $\mathrm{Na}$ ions is larger than that of $\mathrm{Li}$ ions, the volumes of products with $\mathrm{Na}$ significantly expand in the whole capacity range. Although $\mathrm{Sn}_{4} \mathrm{P}_{3}$ and $\mathrm{SnS}$ have large theoretical capacities, $\mathrm{Sn}_{4} \mathrm{P}_{3}$ suffers from larger volume expansion than $\mathrm{SnS}$, especially for Na-ion battery applications.

\section{Author contributions}

Hiroki Kotaka: conceptualization, data curation, formal analysis, investigation, methodology, software, visualization, and writing - original draft; Hiroyoshi Momida and Tamio Oguchi: funding acquisition, project administration, resources, supervision, and writing - review and editing.

\section{Conflicts of interest}

There are no conflicts to declare.

\section{Acknowledgements}

We thank Ayuko Kitajou and Shigeto Okada for invaluable discussion on experimental aspects. This work was partially supported by the Elements Strategy Initiative for Catalysts and Batteries (ESICB) (Grant No. JPMXP0112101003) of the Ministry of Education, Culture, Sports, Science, and Technology (MEXT). The computation in this work was partly carried out using the facilities of the Supercomputer Center, Institute for Solid State Physics, University of Tokyo.

\section{Notes and references}

1 J. B. Goodenough and Y. Kim, Chem. Mater., 2010, 22, 587-603.
2 R. Marom, S. Francis Amalraj, N. Leifer, D. Jacob and D. Aurbach, J. Mater. Chem., 2011, 21, 9938-9954.

3 V. Etacheri, R. Marom, R. Elazari, G. Salitra and D. Aurbach, Energy Environ. Sci., 2011, 4, 3243-3262.

4 N. Nitta, F. Wu, J. T. Lee and G. Yushin, Mater. Today, 2015, 18, 252-264.

5 M. Datt Bhatt and C. O'Dwyer, Phys. Chem. Chem. Phys., 2015, 17, 4799-4844.

6 N. Yabuuchi, K. Kubota, M. Dahbi and S. Komaba, Chem. Rev., 2014, 114, 11636-11682.

7 M. H. Han, E. Gonzalo, G. Singh and T. Rojo, Energy Environ. Sci., 2015, 8, 81-102.

8 K. Kubota and S. Komaba, J. Electrochem. Soc., 2015, 162, A2538-A2550.

9 Y. Zhao, L. P. Wang, M. T. Sougrati, Z. Feng, Y. Leconte, A. Fisher, M. Srinivasan and Z. Xu, Adv. Energy Mater., 2017, 7, 1601424.

10 H. Kim, J. C. Kim, M. Bianchini, D.-H. Seo, J. RodriguezGarcia and G. Ceder, Adv. Energy Mater., 2018, 8, 1702384.

11 H. D. Yoo, I. Shterenberg, Y. Gofer, G. Gershinsky, N. Pour and D. Aurbach, Energy Environ. Sci., 2013, 6, 2265-2279.

12 M. Mao, T. Gao, S. Hou and C. Wang, Chem. Soc. Rev., 2018, 47, 8804-8841.

13 K. Kubota, M. Dahbi, T. Hosaka, S. Kumakura and S. Komaba, Chem. Rec., 2018, 18, 459-479.

14 P. Ge and M. Fouletier, Solid State Ionics, 1988, 28-30, 1172-1175.

15 D. A. Stevens and J. R. Dahn, J. Electrochem. Soc., 2001, 148, A803-A811.

16 R. C. Asher, J. Inorg. Nucl. Chem., 1959, 10, 238-249.

17 R. Lalini, U. Uma, T. Sheela, M. Ganesan and N. G. Renganathan, Ionics, 2009, 15, 301-307.

18 S.-H. Yu, X. Feng, N. Zhang, J. Seok and H. D. Abruna, Acc. Chem. Res., 2018, 51, 273-281.

19 A. Kitajou, J. Yamaguchi, S. Hara and S. Okada, J. Power Sources, 2014, 247, 391-395.

20 N. Dimov, A. Nishimura, K. Chihara, A. Kitajou, I. D. Gocheva and S. Okada, Electrochim. Acta, 2013, 110, 214-220.

21 M. Zhou, L. Zhao, A. Kitajou, S. Okada and J. Yamaki, J. Power Sources, 2012, 203, 103-108.

22 T. Oguchi and H. Momida, J. Phys. Soc. Jpn., 2013, 82, 065004.

23 H. Momida, T. Yamashita and T. Oguchi, J. Phys. Soc. Jpn., 2014, 83, 124713.

24 H. Momida, A. Kitajou, S. Okada, T. Yamashita and T. Oguchi, J. Phys. Soc. Jpn., 2015, 84, 124709.

25 A. Kitajou, Y. Ishado, T. Yamashita, H. Momida, T. Oguchi and S. Okada, Electrochim. Acta, 2017, 245, 424-429.

26 H. Kotaka, H. Momida, A. Kitajou, S. Okada and T. Oguchi, J. Comput. Chem., Jpn., 2019, 18, 78-83.

27 H. Kotaka, H. Momida, A. Kitajou, S. Okada and T. Oguchi, Chem. Rec., 2019, 19, 811-816.

28 V. L. Chevrier and G. Ceder, J. Electrochem. Soc., 2011, 158, A1011-A1114.

29 S. Komaba, Y. Matsuura, T. Ishikawa, N. Yabuuchi, W. Murata and S. Kuze, Electrochem. Commun., 2012, 21, 65-68. 
30 L. Baggetto, P. Ganesh, R. P. Meisner, R. R. Unocic, J.-C. Jumas, C. A. Bridges and G. M. Veith, J. Power Sources, 2013, 234, 48-59.

31 K. Dai, H. Zhao, Z. Wang, X. Song, V. Battaglia and G. Liu, J. Power Sources, 2014, 263, 276-279.

32 D.-H. Nam, K.-S. Hong, S.-J. Lim, T.-H. Kim and H.-S. Kwon, J. Phys. Chem. C, 2014, 118, 20086-20093.

33 J. W. Wang, X. H. Liu, S. X. Mao and J. Y. Huang, Nano Lett., 2012, 12, 5897-5902.

34 B. A. Boukamp, G. C. Lesh and R. A. Huggins, J. Electrochem. Soc., 1981, 128, 725.

35 D. Su, C. Wang, H. Ahn and G. Wang, Phys. Chem. Chem. Phys., 2013, 15, 12543-12550.

36 D. Su, X. Xie and G. Wang, Chem. - Eur. J., 2014, 20, 3192-3197.

37 C. J. Pelliccione, E. V. Timofeeva and C. U. Segre, J. Phys. Chem. C, 2016, 120, 5331-5339.

38 T. Zhou, W. K. Pang, C. Zhang, J. Yang, Z. Chen, H. K. Liu and Z. Guo, ACS Nano, 2014, 8, 8323-8333.

39 A. M. Tripathi and S. Mitra, RSC Adv., 2015, 5, 23671-23682.

40 G. G. Kumar, K. Reddy, K. S. Nahm, N. Angulakshmi and A. M. Stephan, J. Phys. Chem. Solids, 2012, 73, 1187-1190.

41 Y. C. Lu, C. Ma, J. Alvarado, N. Dimov, Y. S. Meng and S. Okada, J. Mater. Chem. A, 2015, 3, 16971-16977.

42 A. Ueda, M. Nagao, A. Inoue, A. Hayashi, Y. Seino, T. Ota and M. Tatsumisago, J. Power Sources, 2013, 244, 597-600.

43 J. Qian, Y. Xiong, Y. Cao, X. Ai and H. Yang, Nano Lett., 2014, 14, 1865-1869.

44 H. Usui, Y. Domi, K. Fujiwara, M. Shimizu, T. Yamamoto, T. Nohira, R. Hagiwara and H. Sakaguchi, ACS Energy Lett., 2017, 2, 1139-1143.
45 W. Wang, J. Zhang, D. Y. W. Yu and Q. Li, J. Power Sources, 2017, 364, 420-425.

46 S. Gražulis, D. Chateigner, R. T. Downs, A. F. T. Yokochi, M. Quirós, L. Lutterotti, E. Manakova, J. Butkus, P. Moeck and A. Le Bail, J. Appl. Crystallogr., 2009, 42, 726-729.

47 Y. Xu, M. Yamazaki and P. Villars, Jpn. J. Appl. Phys., 2011, 50, 11RH02.

48 G. Kresse and J. Furthmüller, Phys. Rev. B: Condens. Matter Mater. Phys., 1996, 54, 11169-11186.

49 G. Kresse and D. Joubert, Phys. Rev. B: Condens. Matter Mater. Phys., 1999, 59, 1758-1775.

50 J. P. Perdew, K. Burke and M. Ernzerhof, Phys. Rev. Lett., 1996, 77, 3865-3868.

51 P. E. Blöchl, Phys. Rev. B: Condens. Matter Mater. Phys., 1994, 50, 17953-17979.

52 Y. S. Meng and M. E. A. Dompablo, Energy Environ. Sci., 2009, 2, 589-609.

53 S. P. Ong, V. L. Chevrier, G. Hautier, A. Jain, C. Moore, S. Kim, X. Ma and G. Ceder, Energy Environ. Sci., 2011, 4, 3680-3688.

54 A. Urban, D.-H. Seo and G. Ceder, npj Comput. Mater., 2016, 2, 16002 .

55 T. Palaniselvam, C. Mukundan, I. Hasa, A. L. Santhosha, M. Goktas, H. Moon, M. Ruttert, R. Schmuch, K. Pollok, F. Langenhorst, M. Winter, S. Passerini and P. Adelhelm, Adv. Funct. Mater., 2020, 30, 2004798.

56 J. Kim, H. Kim and K. Kang, Adv. Energy Mater., 2018, 8, 1702646.

57 H. Kim, H. Kim, Z. Ding, M. H. Lee, K. Lim, G. Yoon and K. Kang, Adv. Energy Mater., 2016, 6, 1600943. 